\title{
Comparison of episiotomy rates, practice of analgesia and the maternal complications within first 24 hours at two tertiary care units: a comparative, descriptive and a retrospective study
}

\author{
Perera Y A G ${ }^{1}$, Fernando T R N ${ }^{2}$
}

\begin{abstract}
Objectives: Estimate the episiotomy rates at two tertiary care units. Find out the practice of analgesia, prior to performing the episiotomy at the two units. Find out the maternal complications within the first 24 hours after episiotomy at the two units. Compare the outcomes at the two units.
\end{abstract}

Method: Data collected from medical records of all normal vaginal deliveries (NVD); from 21st April to 20th May 2011 at Anuradhapura Teaching Hospital (ATH) and 20th March to 20th May 2012 at labour room C, Castle Street Hospital for Women (CSHW).

Results: The episiotomy rate at ATH was $59 \%$, rate of $85 \%$ for primiparous women and a rate of $29.9 \%$ for multiparous women. The episiotomy rate at CSHW was $96.5 \%$, a rate of $97.8 \%$ for primiparous women and a rate of $94 \%$ for multiparous women. All were medio-lateral episiotomies. Except for two women at CSHW who had epidural analgesia in labour, none of the other women had effective analgesia prior to performing episiotomies at both units. All women had $1 \%-2 \%$ lignocaine infiltrations prior to repair of episiotomy at both the above units. The complications documented within 24 hours due to episiotomy at both units were haematomas, re-suturing, vaginal pack insertions and anaemia.

Conclusion: Episiotomy rate at CSHW was significantly higher than ATH. However at both units the episiotomy rates were higher than the recommended rates and there was no significant difference in the rate of complications at the two units.

Key words: episiotomy rate, child birth practices, analgesia for episiotomy, maternal morbidity

\section{Introduction}

Episiotomy during vaginal delivery was first recommended in 1920s. Episiotomy was initially considered to protect the pelvic floor from lacerations and protect the foetal head from trauma. Therefore it was soon adopted as a standard practice and has been widely used since then. The only surgical procedure more fre-

\footnotetext{
${ }^{1}$ Consultant Obstetrician and

Gynaecologist, Castle Street Hospital for Women, Colombo 8, Sri Lanka.

${ }^{2}$ Lecturer, Department of Obstetrics and Gynaecology, Faculty of Medicine,

Rajarata University, Sri Lanka.

Correspondence: T R N Fernando

E-mail: romaniefernando@yahoo.com

Competing interests: None.
}

quently performed than episiotomy is cutting the umbilical cord. Since mid1980s, there has been a growing body of evidence that episiotomy does not provide these proposed benefits. Evidence over the last two decades show that many women fare better without episiotomy, because the natural tears they suffer are often less severe than the episiotomy ${ }^{1}$. World Health Organization's evidence-based practice for normal birth does not recommend routine episiotomy, and episiotomy is classified as "can be harmful" 2 . The current recommendation is that "routine" episiotomy should be abandoned. Limiting the use of episiotomy is strongly recommended to help protect the integrity of the perineum ${ }^{2}$. Until further research is done, episiotomy should be considered only for certain conditions like; assisted vaginal delivery (forceps or vacuum), preterm delivery, breech delivery, foetal compromise or predicted macrosomia.

Vagina and vulva is composed of muscular and erectile tissue. These tissues are able to distend for birth and contract after parturition. Many of these tissues including blood vessels, nerves and erectile tissues can be damaged by episiotomy. Eventually these erectile tissues will lose its ability to contract and relax and the woman will end up having sexual dysfunctions. No evidence suggests that sexual function is improved by episiotomy; those who have episiotomy may be more likely to have pain with intercourse in the months after pregnancy and are slower to resume having intercourse ${ }^{1}$.

In Sri Lanka more than $95 \%$ of women deliver at hospitals. In some regions hospital delivery is almost $99 \%$. There are trained birth attendants at all hospitals and there is free access to maternity care country wide in all regions. However evidence based child birth practices are not yet popular at many hospitals in Sri Lanka. There were approximately 15,500 deliveries per year at ATH during the year 2010. CSHW is a maternity hospital, in the commercial capital of Sri Lanka. There are five maternity units at CSHW with one specialist obstetrician heading each unit. This study was carried out at one unit (labour room C). There were approximately 3000 deliveries per year during the last three years at labour room $\mathrm{C}$.

The norm in Sri Lanka is to perform episiotomy without anaesthesia, due to the popular belief that episiotomy could be performed painlessly without anaesthesia if it is performed at the peak of a contraction when the 
perineum is at full stretch ${ }^{3}$. This may be the popular belief among Sri Lankan birth attendants; however there are few maternity units where effective analgesia is given prior to performing episiotomy even in Sri Lanka. There is a dearth of published research or audits on child birth practices in Sri Lanka at present.

\section{Method}

A hospital based retrospective study was performed by collecting data from the birth registry and medical records of all singleton, term, and vertex presentations, delivered vaginally. Excluded from the study were preterm births (<37 weeks gestation), nonvertex presentations, multiple pregnancies, vaginal births after caesarean section and instrumental deliveries. Data collected from 21st April to 20th May 2011 at ATH and 20th March to 20th May 2012 at labour room C, CSHW. At ATH data was collected during 30 consecutive days. At CSHW data was collected during 60 consecutive days. Episiotomy rate, type of analgesia used during labour and prior to episiotomy and complications due to episiotomy within 24 hours after delivery were evaluated as outcome measures. Pearson's chi square test was used to compare the proportions and independent sample t-test to compare the means.

\section{Results}

The average age of the women in the study population at ATH was 25.6 years and at CSHW labour room C was 27.8 years. Age range was from 15 years to 42 years at ATH and 16 years to 43 years at CSHW. Average gestation at time of delivery was 39 weeks and 4 days $(\mathrm{SD}=1.5)$ at $\mathrm{ATH}$ and 39 weeks $(S D=1.2)$ at $\mathrm{CSHW}$ (Table 1). Gestation at the time of delivery range was form 37 weeks to 42 weeks and 5 days at ATH and 37 weeks to 41 weeks at CSHW. The average birth weight at ATH was $2860.6 \mathrm{~g}$ $(\mathrm{SD}=189)$ and $3000.7 \mathrm{~g}(\mathrm{SD}=194)$ at CSHW. The ranges of birth weights were $1550 \mathrm{~g}$ to $4110 \mathrm{~g}$ at ATH and $1800 \mathrm{~g}$ to $4530 \mathrm{~g}$ at CSHW. At ATH the rate of macrosomia $(\mathrm{BW}=>3.5 \mathrm{Kg})$ was $8 \%$ and at CSHW was $10 \%$.

There were higher numbers of normal vaginal deliveries, 799, at ATH compared to CSHW labour room C, 283. At ATH out of 799 normal vaginal deliveries 463 women (59\%) had a medio-lateral episiotomy at the time of delivery. At CSHW labour room C, out of 283 normal vaginal deliveries 273 women $(96.5 \%)$ had a mediolateral episiotomy at the time of delivery (Table 2).

There were 406 nulliparous women who had a normal vaginal delivery and 345 of those women had an episiotomy performed at the ATH, with a rate of $85 \%$ (Table 2). There were 135 nulliparous women who had a normal vaginal delivery at CSHW labour room C and 132 of those women had an episiotomy performed, with a rate of $97.8 \%$. There were 393 multiparous women who had a normal vaginal delivery at ATH and 118 of those women had an episiotomy, with a rate of $29.9 \%$. There were 148 multiparous women who had a normal vaginal delivery at CSHW and 139 of those women had an episiotomy, with a rate of $94 \%$ (Table 2).

Average time a woman was in the labour room until delivery was 176 minutes at ATH and 189 minutes at CSHW. The time range was twelve

minutes to 560 minutes at ATH and six minutes to 756 minutes at CSHW (Table 3). Only $29 \%$ of women at ATH and $33 \%$ at CSHW had pethidine as analgesia during labour. Two women had epidural analgesia during labour at CSHW labour room C (Table 3).

At both the above units none of the women who had an episiotomy had local infiltration of lignocaine prior to performing the episiotomy. Two women had epidural analgesia at CSHW labour room C during labour (Table 3).

Complications documented within 24 hours of normal vaginal delivery due to episiotomy were haematomas, re-suturing of the episiotomy, insertion of vaginal packs and haemoglobin less than $8 \mathrm{~g} / \mathrm{dl}$ (Table 4 ). The rate of complications at ATH was $2.59 \%$ and at CSHW 2.93\% (Table 4).

In women who had a normal vaginal delivery and an episiotomy, there were documented five, third degree perineal tears at ATH and two at CSHW (Table 4). The rate of third degree perineal tears was $0.63 \%$ at ATH and $0.71 \%$ at CSHW (Table 4).

There were $124(0.15 \%)$ women at ATH and 94 (0.33\%) women at CSHW who stayed in hospital for more than 24 hours after a normal vaginal delivery (Table 5). The reason for delay in discharge from the hospital, in the majority of women was attributed to as a neonatal problem in the medical records (Table 5).

Table 1. Comparison of gestation, birth weights and age of the women

\begin{tabular}{llll}
\hline & ATH & CSHW & t test \\
\hline Average gestation at delivery & 39 weeks + 4days & 39 weeks & \\
Standard deviation & 1.5 & 1.2 & $\mathrm{P}<0.01$ \\
\hline Average birth weight & $2860.6 \mathrm{~g}$ & $3000.7 \mathrm{~g}$ & $\mathrm{P}<0.01$ \\
Standard deviation & 189 & 194 & \\
\hline Average age & 25.6 years & 27.8 years & $\mathrm{P}<0.01$ \\
Standard deviation & 4.2 & 4.7 &
\end{tabular}


Table 2. Comparison of episiotomy rates at the two units

\begin{tabular}{lccc}
\hline & ATH & CSHW & Pearsons's chi square test \\
\hline Number of NVDs & 799 & 283 & 273 \\
Total number of episiotomies & 463 & $96.5 \%$ & 135 \\
Episiotomy rate & $59 \%$ & $(132)$ & $P<0.01$ \\
Number of primiparous women & 406 & $97.8 \%$ & 138 \\
(number of episiotomies) & $(345)$ & $(139)$ & $\mathrm{P}<0.01$ \\
Episiotomy rate among primparous women & $85 \%$ & $94 \%$ & \\
Number of multiparous women & 393 & $(118)$ & \\
(number of episiotomies) & $29.9 \%$ & & \\
Episiotomy rate among multiparous women & & & \\
\hline
\end{tabular}

Table 3. The time in labour room until delivery, analgesia during labour and analgesia prior to performing episiotomy at the two units

\begin{tabular}{lccc}
\hline & ATH & CSHW & Pearsons's chi square test \\
\hline Average time in labour room until delivery & 176 minutes & 189 minutes & \\
Time range & $12-560$ minutes & $06-756$ minutes & \\
Analgesia during labour & & 94 & P =0.21 \\
Pethidine & 234 & $(33 \%)$ & 02 \\
& $(29 \%)$ & 0 & \\
Epidural & 0 & 0 & \\
Analgesia prior to performing episiotomy & &
\end{tabular}

Table 4. Complications due to episiotomy up to 24 hours after delivery at the two units

\begin{tabular}{|c|c|c|c|}
\hline & ATH & CSHW & Pearsons's chi square test \\
\hline Total number of episiotomies & 463 & 273 & \\
\hline Complications due to episiotomy & 12 & 08 & \\
\hline Rate of complications & $2.59 \%$ & $2.93 \%$ & $P=0.7$ \\
\hline Rate of complications in primiparous women & $\begin{array}{c}3.47 \% \\
(12 / 345)\end{array}$ & $\begin{array}{r}3.78 \% \\
(05 / 135)\end{array}$ & $P=0.9$ \\
\hline Rate of complications in multiparous women & $\begin{array}{c}0 \% \\
(0 / 118)\end{array}$ & $\begin{array}{r}2.27 \% \\
(3 / 139)\end{array}$ & $P=0.1$ \\
\hline Vaginal pack insertion & 09 & 07 & \\
\hline Haematoma & 05 & 03 & \\
\hline Haemoglobin $<8 \mathrm{~g} / \mathrm{dl}$ & 0 & 03 & \\
\hline Re-suturing & 04 & 02 & \\
\hline Third degree perineal tears & 05 & 02 & \\
\hline Rate of 3rd degree perineal tears & $0.63 \%$ & $0.71 \%$ & $P=0.6$ \\
\hline Labial tears & 03 & 01 & \\
\hline Rate of Labial tears & $0.64 \%$ & $0.36 \%$ & $P=0.6$ \\
\hline
\end{tabular}


Table 5. Reasons for hospital stay for more than 24 hours after NVD at the two units

\begin{tabular}{llrl}
\hline $\begin{array}{l}\text { Reason for more than 24hour } \\
\text { hospital stay after a NVD }\end{array}$ & ATH & CSHW & Pearsons's chi square test \\
\hline Neonatal complications & 76 & 58 & $P=0.2$ \\
Maternal complications (other than due to episiotomy) & 36 & 29 & $P<0.01$ \\
Episiotomy complications & 12 & 08 & $P=0.7$ \\
Total & $124(15 \%)$ & $95(33 \%)$ & $P<0.01$ \\
\hline
\end{tabular}

\section{Discussion}

Episiotomy is often called the unkindest cut of all. It has been shown that in developing countries the change of child birth practices from traditional practice to evidence based practice is slow ${ }^{4}$. Compared to other developing countries, Sri Lanka has a better organised and well-structured health care system, that provide maternal and child health care from the primary care level to tertiary care level ${ }^{5}$. Sri Lanka has the lowest maternal and infant mortality rates in South East Asia. However there had been less attention given to child birth practices in terms of pain relief and support to women in labour. The time is ripe to consider giving priority to evidence based child birth practices in Sri Lanka.

There was a significant difference in the mean age, average gestation at delivery and the mean birth weights at the above two units (Table 1). The different induction of labour practices at the two units probably may have made the significant statistical difference of the mean gestation at delivery. The average birth weight (BW) in Sri Lanka by district in 2007, published by government statistics department gives Colombo district's average BW as $2935 \mathrm{~g}$ and for Anuradhapura district $2857 \mathrm{~g}$. Significant statistical difference in the mean birth weights (2860.6g at ATH and $3000.7 \mathrm{~g}$ at CSHW) at the two units can be attributed to the regional variations, like urban/rural populations.

The rate of episiotomy at ATH was 59\% and at CSHW 96.5\% (Table 2). At
ATH the rate of episiotomy was significantly lower compared to CSHW $(p<0.01)$. However at both the units the rate of episiotomy was higher than the recommended rates. WHO guideline on care in normal birth recommends a $10 \%$ rate of episiotomy, to be without harm to the mother or the infant ${ }^{2}$. Katherine Hartmann, et al, states that rates of episiotomy of less than $15 \%$ of spontaneous vaginal births should be immediately within reach ${ }^{1}$. Ian D. Graham, et al, published a study on episiotomy rates around the world concludes, that there is a large variation in the use of episiotomy from country to country, also there are variation within regions of a country ${ }^{6}$. The variation within regions of Sri Lanka too is shown in this study.

In many countries especially united Kingdom and Scandinavian countries the rate of episiotomy has come down drastically during the last two decades. In the year 2010 the rate of episiotomy in UK was $8.3 \%$ and $9.7 \%$ in Sweden in $2003^{7,6}$. A study of the morbidity associated with episiotomy by D S Weerasekera, published in 2002 gives a rate of episiotomy of $51.4 \%$ at the University Unit, Colombo South Teaching Hospital, in Sri Lanka ${ }^{8}$.

Routine episiotomy for nulliparous women is no longer recommended. There is no evidence of benefit from the use of routine episiotomy over restrictive episiotomy even in nulliparous women. Alperin $\mathrm{M}$, et al concludes that episiotomy at first vaginal delivery increases the risk of spontaneous obstetric laceration, including third and fourth degree perineal tears in the subsequent delivery ${ }^{9}$. At both the above units the rate of episiotomy was high among nulliparous women $(85 \%$ at ATH and $97.8 \%$ at CSHW). Yet the rate of episiotomy was significantly higher statistically at CSHW among nulliparous women compared to ATH $(\mathrm{p}<0.01)$. The rate of episiotomy among multiparous women at ATH (29.9\%) was significantly lower compared to CSHW (94\%). It is promising that ATH had a lower rate of episiotomy among multiparous women, as recommended by Lede RL to be justified within $30 \%^{10}$ (Table 2). However there was no significant difference in the rate of complications due to episiotomy at both units $(p=0.7)$. Therefore this may indicate that the rate should come down more than $59 \%$ at ATH to prevent significant maternal complications within first 24 hours postpartum. Rate of episiotomy was lowest among the multiparous women at ATH and there were no episiotomy related complications documented in those women (Table 4).

A study done in Sri Lanka in 2009 states only $8 \%$ of mothers received local anaesthesia prior to performing an episiotomy, but $99 \%$ received local anaesthesia prior to episiotomy repair at North Colombo Teaching Hospital, in Sri Lanka ${ }^{11}$. National Institute for Health and Clinical Excellence (NICE), United Kingdom guideline on intrapartum care (2007) recommends that tested effective analgesia should be 
provided prior to carrying out an episiotomy, except in an emergency due to acute foetal compromise. WHO guideline on episiotomy recommends use of local infiltration of lignocaine or pudendal block prior to performing episiotomy. It was unfortunate to find out none of the women at ATH or CSHW had effective analgesia prior to episiotomy, except in two women who had epidural anaesthesia at CSHW (Table 3).

Majority of the women had been in the labour room for approximately three hours (176 minutes at ATH and 189 minutes at CSHW) at the above units, until delivery (Table 3). Some of the women $(29 \%$ of women at ATH and $33 \%$ at CSHW) had pethidine intramuscular injections as analgesia during labour (Table 3). Only few women will request effective analgesia during labour in Sri Lanka. The best pain relief most of them would get is intramuscular pethidine ${ }^{12}$. Epidural analgesia for pain relief in labour is only available in few tertiary care units in Sri Lanka. Although many assume that Sri Lankan women prefer natural labour, further research should be done to confirm women's attitudes and beliefs regarding pain relief in labour.

The documented complication rate due to episiotomy at ATH was 2.59\% and at CSHW was $2.93 \%$ (Table 4 ). There was no statistically significant difference of complications due to episiotomy at the two units $(p=0.7)$. The complications documented in the medical records of the above two units have been previously reported in literature. Only at CSHW that low haemoglobin $(<8 \mathrm{~g} / \mathrm{dl})$ was documented in three women who had excessive bleeding / haematoma formation following episiotomy and had undergone re-suturing of the episiotomy (Table 4). These three women had normal pre delivery haemoglobin levels and needed blood transfusions after delivery. There was one woman at CSHW labour room C, who had a normal vaginal delivery had to have re-suturing of the episiotomy twice at the operating theatre and also had a balloon catheter temponade applied to the vagina for 24 hours to control the bleeding.

Vaginal pack insertion was the most frequently done additional procedure at both units following episiotomies which were complicated by haematomas or excessive per vaginal bleeding (Table 4). There were nine vaginal pack insertions at ATH; all were done at the labour room. There were seven vaginal packs insertion at CSHW; this includes one case of balloon temponade application at the operating theatre. There were four re-suturing of the episiotomy done at ATH at the labour room. There were two resuturing of episiotomy done at operating theatre at CSHW. There were five haematomas following episiotomy at ATH and three at CSHW (Table 4). Those women who had a haematoma either had a vaginal pack, re-suturing of the episiotomy or a balloon temponade. The three women with haematomas at CSHW had haemoglobin $<8 \mathrm{~g} / \mathrm{dl}, 24$ hours after delivery.

Woolley systematically reviewed the literature from 1980 to 1994 concluded that a medio-lateral or midline episiotomy does not prevent damage to the anal sphincter and its sequelae $^{13}$. Many studies have found that episiotomy is the factor with the strongest association with a third or fourth degree laceration, especially in the presence of a midline episiotomy ${ }^{14}$, ${ }^{15}$. Severe perineal tears which involve the anal sphincters and/or the rectal mucosa are identified in $0.6-0.9 \%$ of vaginal deliveries as reported in literature ${ }^{16}$. At the above two units third degree perineal tears (ATH $0.63 \%$ and CSHW $0.71 \%$ ) were within the range of reported incidence in the literature (Table 4). There were three $(0.64 \%)$ labial tears documented at ATH while at CSHW there was one $(0.36 \%)$. There was no significant difference of the occurrence of perineal and labial tears at both units $(\mathrm{p}=0.7)$.

Although perineal pain is common after an episiotomy, none of the medical records had documented this complication at both the above units. The post episiotomy analgesia recorded in the uncomplicated cases at both units was paracetamol $1000 \mathrm{mg}$ on request by the woman when in pain. There were no routine analgesia requests in the majority of the women except in the women with post op complications. The burden of mortality and morbidity related to pregnancy and childbirth remains concentrated in developing countries ${ }^{17}$.

Hospital stay for more than 24 hours after NVD at CSHW was significantly higher than ATH (Table 5). This significant difference is attributed to maternal complications other than episiotomy mainly medical complications. All women who had a complication due to episiotomy had stayed more than 24 hours in the hospital after a NVD.

\section{Conclusions}

The rate of episiotomy at CSHW was significantly higher than ATH. However there was no significant difference in the rate of complications due to episiotomy. This may be due the higher rates of episiotomy than the recommended $10-15 \%$ at both units. Practise of analgesia for episiotomy was insufficient at both units.

We suggest that Sri Lankan birth attendants should be trained and educated to improve evidence based child birth practices, with more emphasis given to effective pain relief for episiotomy and labour. The principles of evidence-based practice are to encourage health professionals to use practices with proven benefit and eliminate the use of those shown to be ineffective or harmful. Effective implementation of safe and effective practices like restrictive episiotomy should lead to a reduction in maternal mortality and morbidities. Audits should be encouraged on labour ward practices such as episiotomy rates, complications due to episiotomy and practice of analgesia during labour and episiotomy. This will hopefully improve the safety and standards of child birth practices in Sri Lanka. 


\section{Acknowledgements}

Prof. Malini Udupihille, Acting Dean, Faculty of Medicine and Allied Sciences, Rajarata University of Sri Lanka, for the administrative support provided, Dr.W. M. T. B. Wijekoon, Director ATH (2011), for granting permission to do the research at ATH, Dr. A. Amarasiri, Consultant Obstetrician and Gynaecologists, ATH (2011), Dr. A. M. Jayasiri, Consultant Obstetrician and Gynaecologist, ATH (2011), Dr. M. A. J. S. Fernando, Medical Officer, for Assisting in Data Collection at CSHW, labour room C, Dr. P. B. Samarasinghe, Medical Officer, for Assisting in Data Collection at CSHW, labour room C, Dr. A. N. Wijayanayake, Senior Lecturer, Department of Industrial Management, University of Kelaniya, Sri Lanka, for Assisting in Literature Survey, Students of group 8, batch 2005/06 Faculty of Medicine, Rajarata University, for Collecting Data from the ATH, Dr. P. K. Abeysundara, Medical Officer, for Assistance given for statistical analysis.

\section{REFERENCES}

1. Hartmann $K$, Viswanathan $M$, Palmieri R, Gartlehner G, Thorp J, Lohr KN. Outcomes of Routine Episiotomy. A Systematic Review: JAMA. 2005; 293(17): 2141-8.

2. Care in Normal Birth; practical guide, $\mathrm{WHO} /$
FRH/MSM/96.24, Page 29-35. http:// whqlibdoc.who.int/hq/1996/WHO_ FRH_ MSM_96.24.pdf

3. Senanayake H, Adikaram R, Alwis $\mathrm{T}$, Ahmad M, Gunathilaka BMJP. Perception of pain during episiotomy in a tertiary care centre in Sri Lanka. Ceylon Medical Journal 2011; 56: 41-2.

4. The SEA-ORCHID Study Group; Use of Evidence-Based Practices in Pregnancy and Childbirth. South East Asia Optimising Reproductive and Child Health in Developing Countries Project. PLoS ONE 3(7): e2646. doi:10.1371/journal.pone.0002646. http:// www.plosone.org/article/info:doi/10.1371/ journal.pone.0002646

5. Rannan-Eliya RP, Sikurajapathy L. Sri Lanka: "Good Practice" in Expanding Health Care Coverage. Research Studies Series 3: 19-20. http://65.181.149.26/publications/docs/ RSS0903.pdf

6. Graham ID, Carroli G, Davies C, Medves JM. Episiotomy Rates Around the World: An Update. BIRTH 32: 3, September 2005; 219-24.

7. NHS Maternity Statistics, England: 201011. http://www.ic.nhs.uk/pubs/maternity1011

8. Weerasekera DS, Udugama SG. The Ceylon Journal of Medical Science 2002; 45: 77-81.

9. Alperin M, Krohn MA, Parviainen K. Episiotomy and increase in the risk of obstetric laceration in a subsequent vaginal delivery. Obstet Gynecol. 2008 Jun; 111(6): 1274-8.

10. Lede RL, Belizán JM, Carroli G. Is routine use of episiotomy justified? Am J Obstet- gynecol 1996; 174: 1399-402.

11. Kularathne IDHP, Jayawardana AMS, Jayaweera GNP, Kamburugamuwa KLAM, Karunarathne CB, Keshika RW, et al. Episiotomy Care of Mothers in the Labour Room at North Colombo Teaching Hospital. Young Researchers Symposium 2009: Abstract 4.

12. Warnakulasuriya, A. (2010). Obstetric anaesthesia. Sri Lankan Journal of Anaesthesiology: 18(1), 5-9. doi:10.4038/ slja.v18i1.1553.

13. Woolley RJ. Benefits and risks of episiotomy: a review of the English-language literature since 1980. I and II. Obstet Gynecol Surv 1995; 50: 806-35.

14. Carroli G, Mignini L. Episiotomy for Vaginal Delivery. The Cochrane Database of Systematic Reviews 2009, Issue 1.

15. Klein MC, Gauthier RJ, Robbins JM, et.al. Relationship of episiotomy to perineal trauma and morbidity, sexual dysfunction and pelvic floor relaxation. Am J Obstet Gynecol 1994; 171:591-8.

16. Juul L, Gerhard BT. Risk factors for thirdand fourth-degree perineal tears during vaginal delivery. Urogynaecologia 2011; 25: http://www.urogynaecologia.it/index.php/uij/ article/view/uij.2011.e2/64

17. Department of Reproductive Health and Research World Health Organization (2004) Maternal mortality in 2000: estimates developed by WHO, UNICEF and UNFPA. Geneva: WHO. [http://www.who.int/ reproductive-health/pblications/ maternal_mortality_2000/index.html]. 